\title{
Drilling Challenge for the NanTro Fault Zone Drilling by Chikyu
}

by Kazuhiro Higuchi and Shomei Kobayashi

doi:10.2204/iodp.sd.s01.37.2007

The Chikyu is a riser-equipped, dynamically positioned, scientific drill ship owned and operated by the Japan Agency for Marine-Earth Science and Technology (JAMSTEC). Chikyu was delivered in 2005 and is preparing for the IODP scientific drilling operation (Curewitz et al., 2006; Taira, 2005). For specifications, see Table 1.

To access scientific targets, deeper than ever before beneath the deep-sea floor, the target was set to $7000 \mathrm{~m}$, in water depths initially up to $2500 \mathrm{~m}$, eventually as deep as $4000 \mathrm{~m}$ (Taira, 2005). To drill deeper, weighted mud is required to keep holes stable within the pressure window higher than pore pressure and lower than fracture pressure. For the circulation of mud and transportation of gas/cuttings, specially designed risers are prepared for Chikyu. The high pressure BOP (Blow Out Preventer) aboard Chikyu is designed to control the borehole pressure balanced with mud hydrostatic pressure, even in occasional under-balanced conditions. Also, high-strength drill pipes are necessary to access deeper targets to endure high torque and high tensile stress. These drill pipes are designed to have large inside diameters to pass through the wireline retrievable core barrel. Several sizes of cemented casings are required to drill through various pressure/stress zones or fractures.

Although Chikyu has various state of the art equipment as described above for the deeper scientific drilling, well planned engineering is the key to achieving the scientific targets without encountering drilling hazards. Potential drilling hazards might be posed by sea and weather conditions, weak formation, shallow gas, low fracture gradients, abnormal pressure, high stress, fractured faults, high temperatures, or human error (Fig. 1).

The drilling engineer's responsibility is to accomplish the objective of the hole, safely, efficiently and economically. The objective might be the access to the target position, depth or formation, data from wireline logging or LWD, samples of core/cuttings/gas/water, testing, or the deployment of monitoring systems.

Table 1: Chikyu Specifications

\begin{tabular}{ll} 
Overall Length & $210 \mathrm{~m}$ \\
Breadth (Mid) & $38 \mathrm{~m}$ \\
\hline Depth (Mid) & $16.2 \mathrm{~m}$ \\
Draft & $9.2 \mathrm{~m}$ \\
Derrick Height & $107 \mathrm{~m}$ \\
Drillstring Length & $10,000 \mathrm{~m}$ \\
Accommodation & 150 \\
Speed & $\sim$ Symbol 10kt
\end{tabular}

Keys to the success of any drilling are to have accurate pressure, temperature and geology estimation, a good understanding of what might happen from offset wells, a choice of field-proven reliable tools and procedures, a simple design, preparation for back-up tools and contingency plans, and good communication with related people.

NanTroSEIZE (Tobin and Kinoshita, 2006) will commence from 2007 to drill a complex splay fault zone. The challenge lies in the lack of offset well data and difficulties regarding predictions of pressure, temperature, and stress. NanTroSEIZE drilling is the first scientific drilling by Chikyu and the first access to a large active splay fault of a plateboundary thrust.

As scientific success is not achieved without drilling success, cooperation and communication between drilling engineers and scientists are essential points to consider.

\section{References}

Curewitz, D., Kuramoto, S., and Kawamura, Y., 2006. Drilling vessel Chikyu: Status, capabilities, and current operations. Sci. Drill., 3:52-53.

Taira, A., 2005. The Chikyu: Meeting the challenges of a new scientific drilling era. Sci. Drill., 1:32-33.

Tobin, H. and Kinoshita, M., 2006. NanTroSEIZE: The IODP Nankai Trough seismogenic zone experiment. Sci. Drill., 2:23-27.

\section{Authors}

Kazuhiro Higuchi and Shomei Kobayashi, Center for Deep Earth Exploration (CDEX), Japan Agency for MarineEarth Science and Technology (JAMSTEC), 3173-25 Showamachi, Kanazawa-ku, Yokohama, Kanagawa 236-0001, Japan, e-mail: higuchik@jamstec.go.jp.

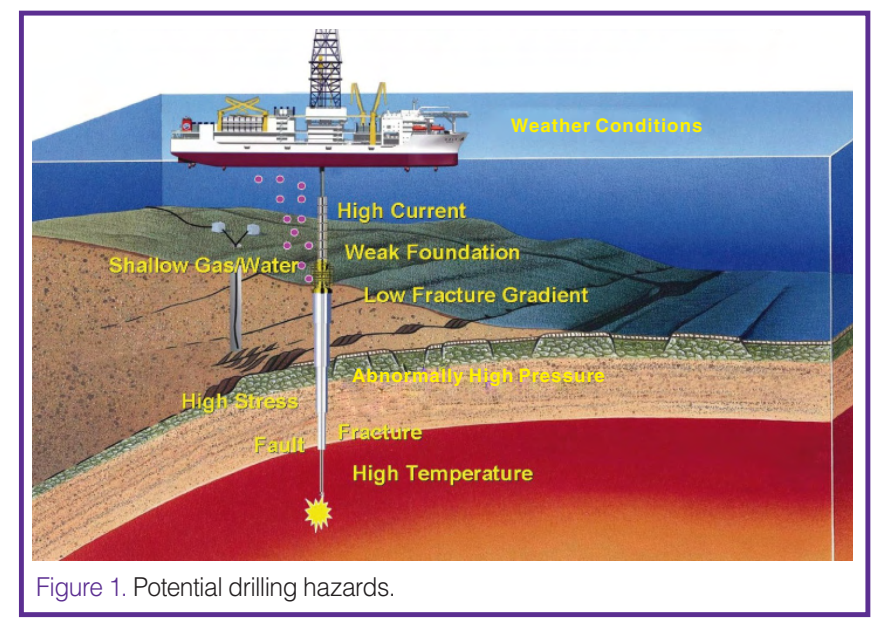

